\title{
Prefrontal cortical blood flow and cognitive function in Huntington's disease
}

\author{
DANIEL R WEINBERGER, KAREN F BERMAN, MARY IADAROLA, \\ NAOMI DRIESEN, RONALD F ZEC \\ From the Clinical Brain Disorders Branch, Intramural Research Program, National Institute of Mental Health \\ and Behavioural Neurology Service, St Elizabeth's Hospital, Washington DC, USA
}

SUMMARY To examine the relationship between cortical physiology and dementia in Huntington's disease, rCBF during three different behavioural conditions, one of which emphasised prefrontal cognition, was determined by xenon-133 inhalation in 14 patients with Huntington's disease and in matched controls. Cortical rCBF was not reduced in Huntington's disease patients even while they manifested overt prefrontal-type cognitive deficits. Caudate atrophy on CT and rCBF were significantly correlated, but only during the prefrontal behaviour where the correlation was positive. These results suggest a qualification of the subcortical dementia concept as applied to Huntington's disease and implicate an interaction between pathology that is subcortical and cognitive function that is cortical.

Intellectual deterioration is a hallmark of Huntington's disease that in some patients predates the development of chorea. ${ }^{12}$ While dementia in advanced cases is attributable to widespread degenerative changes in the brain, especially the frontal cortex, ${ }^{134}$ the pathophysiology of intellectual changes seen in the early stages of the illness is unclear. Neuropathological and neurochemical changes in the cortex of early cases are usually mild and occasionally absent. $^{356}$ Evidence of frontal atrophy on CT scan does not reliably predict degree of dementia. ${ }^{7-10}$ Moreover, and perhaps most surprising of all, studies of brain glucose metabolism using positron emission tomography (PET) have found that frontal cortex metabolic rates tend to be normal in other than advanced cases. ${ }^{10-13}$

In spite of this lack of direct neuropathological data, the concept of the dementia of Huntington's disease being a frontal lobe type dementia has a long history and is supported by considerable indirect evidence. Two of Huntington's original case descriptions include references to social inappropriateness and poor judgement suggestive of prefrontal dysfunction. ${ }^{14}$ More recently, studies of the behavioural

Address for reprint requests: Dr D R Weinberger, MD, Clinical Brain Disorders Branch, National Institute of Mental Health, St Elizabeth's Hospital, Washington DC 20032, USA.

Received 18 March 1987. Accepted 8 May 1987 changes and the pattern of deficits on formal neuropsychological testing seen in this illness have stressed the similarity of the results to findings in patients with unequivocal frontal lobe disease. ${ }^{7815-19}$

An alternative and increasingly popular view is that the dementia of Huntington's disease is a so-called "subcortical dementia" linked directly to pathology of the basal ganglia. ${ }^{20-24}$ This view implies that certain intellectual functions are processed in the basal ganglia or at least that they are fundamentally dependent on the integrity of the basal ganglia. The "subcortical" dementia concept is controversial and primarily theoretical. ${ }^{232526}$ There are little direct experimental data to support it. While some studies have shown a relationship between caudate atrophy on CT and intellectual function, ${ }^{8}$ others have not. ${ }^{79-11}$ Likewise, despite consistent PET findings of reduced caudate glucose metabolism, ${ }^{10-13}$ the magnitude of the reduction has not consistently predicted the degree of dementia. ${ }^{10}$

In this report we describe a potentially more informative approach to exploring the pathophysiology of the dementia of Huntington's disease. It involves the simultaneous assessment of prefrontal cortical blood flow and prefrontal cognitive function. Information about how these parameters are related in Huntington's disease may help clarify the pathophysiology of the cognitive impairment. The findings suggest that prefrontal type cognitive deficits are not the result of 
intrinsic prefrontal disease or dysfunction but reflect the impact of caudate pathology on normal prefrontal physiology.

\section{Methods}

Subjects Fourteen patients with adult onset Huntington's disease (seven men, seven women) ages 25 to 61 (mean 41.9) participated in the study. Diagnosis was made on the basis of a positive family history, the presence of chorea, deterioration in cognitive function, and in most cases (see below) presence of caudate atrophy on CT scan. Complete neurological examinations, automated blood chemistry analyses, thyroid function tests, and peripheral blood smears were not suggestive of other aetiologies of the abnormal movements. The onset of chorea as determined by historical accounts ranged from 1 to 19 years (mean 6.4), and the diagnosis had been made from 1 month to 10 years (mean 3.7 ) before the study. According to the staging criteria of Shoulson and Fahn, ${ }^{27}$ three patients were stage I, seven were stage II, three were stage III, and one was stage IV. Two patients required continuous institutional care and were taking haloperidol $5 \mathrm{mg}$ per day. The rest of the group were outpatients and were medication-free.

Fourteen age and sex matched normal volunteers (seven men, seven women, mean age $42 \cdot 7$, range 22 to 68 ) comprised the control group. These individuals had no history of neurological, psychiatric, or systemic medical illness. There were no significant differences between patients and controls in age, handedness (all right handed), height, weight, resting pulse, and blood pressure. The controls had completed more years of education (mean \pm S.D.: $16 \cdot 1+2 \cdot 8 \mathrm{v}$. $13 \cdot 3+3 \cdot 5$, $\mathrm{p}<0.05, t$ test $)$.

rCBF Technique rCBF was determined by the xenon-133 inhalation method developed by Obrist et $a l^{28}$ and modified by Deshmukh and Meyer. ${ }^{29}$ We have instituted several further modifications in the practical application of this technique which are detailed elsewhere. ${ }^{30}$ They involve primarily a method for reproducible placement of extracranial radiation detectors to facilitate repeat studies, having subjects in a seated position, and the use of a snorkel-like mouthpiece and soft nose clamp. In addition, we have adapted a topographic mapping technique for pictorial display of the data that is described elsewhere. ${ }^{30}{ }^{31}$ The rCBF data presented here consist of initial slope (IS) values derived from clearance curves for 32 cortical areas surveyed by 32 extracranial radiation detectors. This unitless, index measure has been defined and validated by Obrist and Wilkinson as indicative of grey matter blood flow. ${ }^{32}$ The approximate region of cortex monitored by each detector has been previously determined by their relationship to standard international 10-20 EEG lead placements. ${ }^{30}$

$r C B F$ test conditions Each subject underwent three consecutive rCBF procedures separated by at least 30 minutes and carried out in either a morning or afternoon session. The testing took place in a dimly lit and quiet room. The first condition was the "resting state" in which they were told to remain awake, motionless, and to keep their eyes closed.

The second and third rCBF procedures, each performed after correction for background radioactivity, were administered during the performance of mental activation tasks which were presented in counterbalanced sequence to control for the possibility of an order effect. ${ }^{33} 34$ These tasks are described in greater detail elsewhere ${ }^{30}$ The activation paradigms began approximately 1 minute before xenon inhalation and continued throughout the entire 12 minute rCBF measurement period.

One paradigm was an automated version of the Wisconsin Card Sorting Test (WCS), an abstract reasoning, problemsolving test that involves achieving abstract sets, then maintaining and changing these sets when appropriate as determined by feedback. The test procedure and method for scoring are as described by Heaton. ${ }^{35}$ This test was used because it is a relatively well validated measure of prefrontal cortical cognitive function. ${ }^{36-39}$ Patients with focal lesions involving particularly dorsolateral prefrontal cortex (DLPFC) consistently do worse on this test than patients with cortical lesions elsewhere. Furthermore, we have shown in a large sample of normal individuals that performance on the WCS is associated with an increase in rCBF that is greatest in dorsolateral prefrontal cortex. ${ }^{30}$ While it is unusual for normal individuals to have difficulty with this test, patients with Huntington's disease typically do poorly on it. ${ }^{719}$

The other task was a simple automated number matching (NM) procedure performed on the identical apparatus as in the WCS. This task served two purposes: it was a nonprefrontally specific and simple mental activity that patients with Huntington's disease could complete without obvious difficulty; and it served as an active baseline state against which rCBF during the WCS could be compared. In keeping with this latter purpose, the NM was conceived as an individualised control for aspects of the WCS-rCBF experience other than DLPFC-specific cognitive function. These included the minimal finger movement involved in pressing a switch to make a response, the eye scanning and visual stimulation involved, and the emotional and psychological experience of taking a test during which rCBF is measured. In theory, these factors remained relatively constant from one task to another. We have previously found that by examining differences in $\mathrm{rCBF}$ between the $\mathrm{NM}$ and the WCS, those aspects of the WCS rCBF that are specific to the WCS may be better isolated. ${ }^{30}$

Computed tomography High resolution CT scans that had been performed within 6 months of the rCBF procedure were available for 10 patients. Caudate atrophy was assessed using the frontal horn-caudate ratio (FCR), ${ }^{940}$ a measure that varies inversely with degree of caudate atrophy (that is, lower ratios correspond to more atrophy). One patient had a frontal-caudate ratio of $2 \cdot 1$. the only value that fell within the normal range. ${ }^{90}$ The other patients had values ranging from $1 \cdot 2$ to 1.6 .

Peripheral physiological data Several peripheral physiological measures were continuously monitored on a polygraph during each $\mathrm{rCBF}$ procedure, including pulse rate, respiratory rate, skin conductance (GSR), and end expiratory partial pressure of carbon dioxide ( $\mathrm{pCO} 2)$. The autonomic measures were used to evaluate a possible effect of nonspecific arousal and anxiety on rCBF data. Polygraphic recordings were scored as previously described. ${ }^{30}$ 


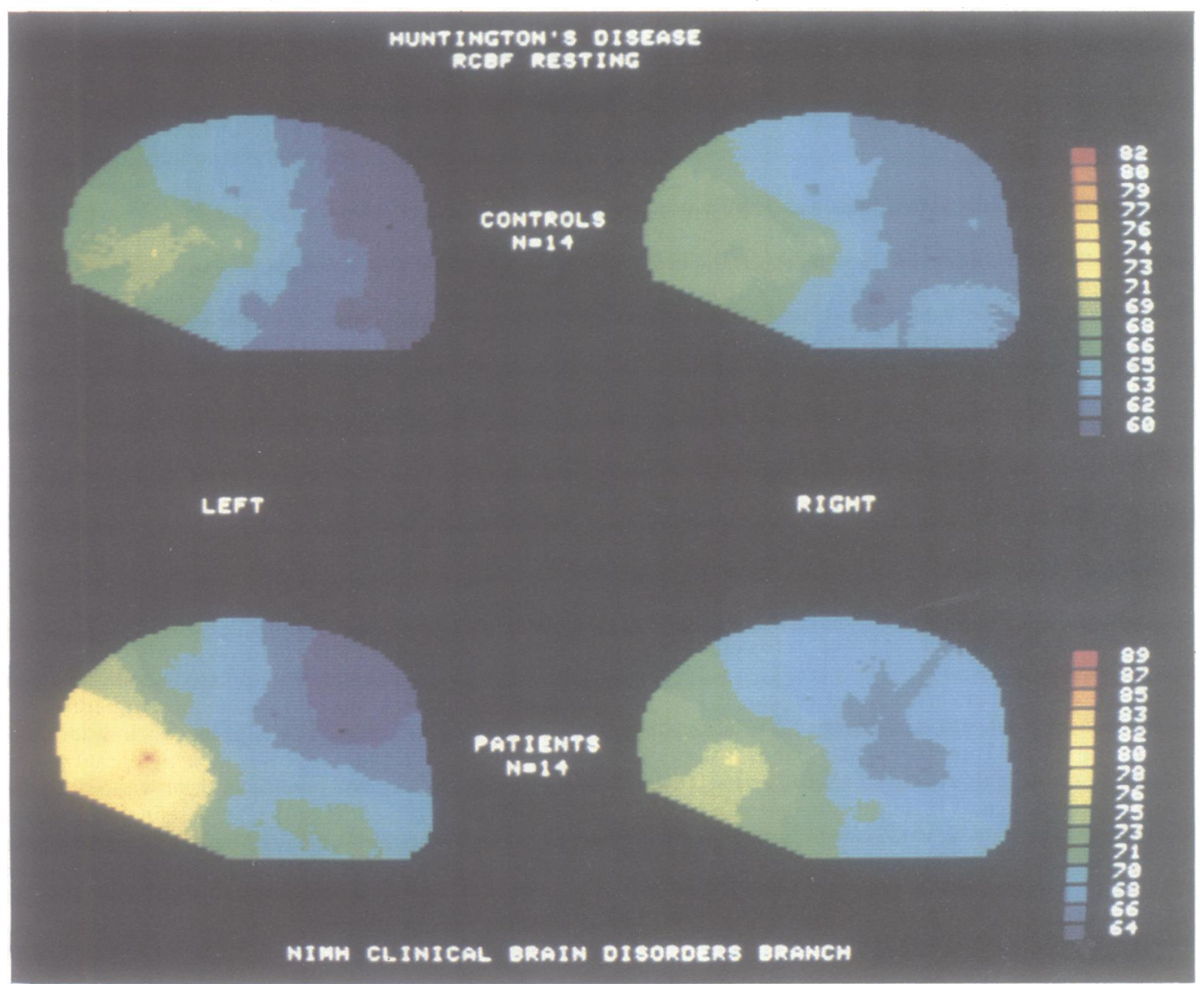

(a)

Fig 1 Topographic gray-matter group mean $\mathrm{CCBF}$ maps of left and right hemispheres showing lateral view of cortex with frontal pole pointing to left. Colour scale is keyed to initial slope values except in (d) where it indicates percentage change relative to NM baseline. Note that colour scales are anchored to different values for controls and Huntington's disease patients. However, the scales are identical for each subject group regardless of behavioural condition. $r C B F$ values are $\mathrm{pCO}_{2}$ corrected. Three behavioural conditions are shown: $(a)$ is during resting; on following pages (b) upper right is during the number matching (NM) test; (c) is during the Wisconsin Card Sorting Test (WCS). (d) shows percent change in $\mathrm{CCBF}$ during $W C S$ as compared with during $N M$.

Statistical analyses Each rCBF test condition was analysed separately. Three types of analyses were performed.

(1) Regional analysis A region-by-region analysis of absolute $\mathrm{rCBF}$ involved collapsing the $\mathbf{3 2}$ individual grey matter (IS) values into five functionally meaningful regions: prefrontal, precentral, temporal, parietal, and parieto-occipital. To keep the number of variables appropriate for the sample sizes, the regions were not subdivided according to hemisphere. The rCBF value for each region was the mean of the individual detector values comprising the region. Across group analysis was done by a conservative multivariate analysis of variance (MANOVA) no repeated measures design with the five regional values as the variables and by univariate ANOVA for each region independently.
The interpretation of absolute $\mathrm{rCBF}$ data is complicated by the effect of blood pCO2. Since rCBF varies directly with pCO2, ${ }^{41-43}$ it is possible that group rCBF differences could be an artifact of ventilatory differences. One approach to this problem has been to apply a correction factor 294445 but the magnitude of this factor is controversial. ${ }^{41-44}$ Furthermore, while it is clear that acute changes in pCO2 alter rCBF, ${ }^{4-44}$ the impact of chronic changes is less certain. ${ }^{46}$ To further complicate this issue, $\mathrm{pCO} 2$ values in expired air may not accurately reflect arterial pCO2, because any leakage involved in gas delivery will result in lower expired air $\mathrm{pCO} 2$ values. For these reasons, the role of $\mathrm{pCO} 2$ values in this study is problematic. We have chosen to present both pCO2 corrected and uncorrected data. Where pCO2 cor- 


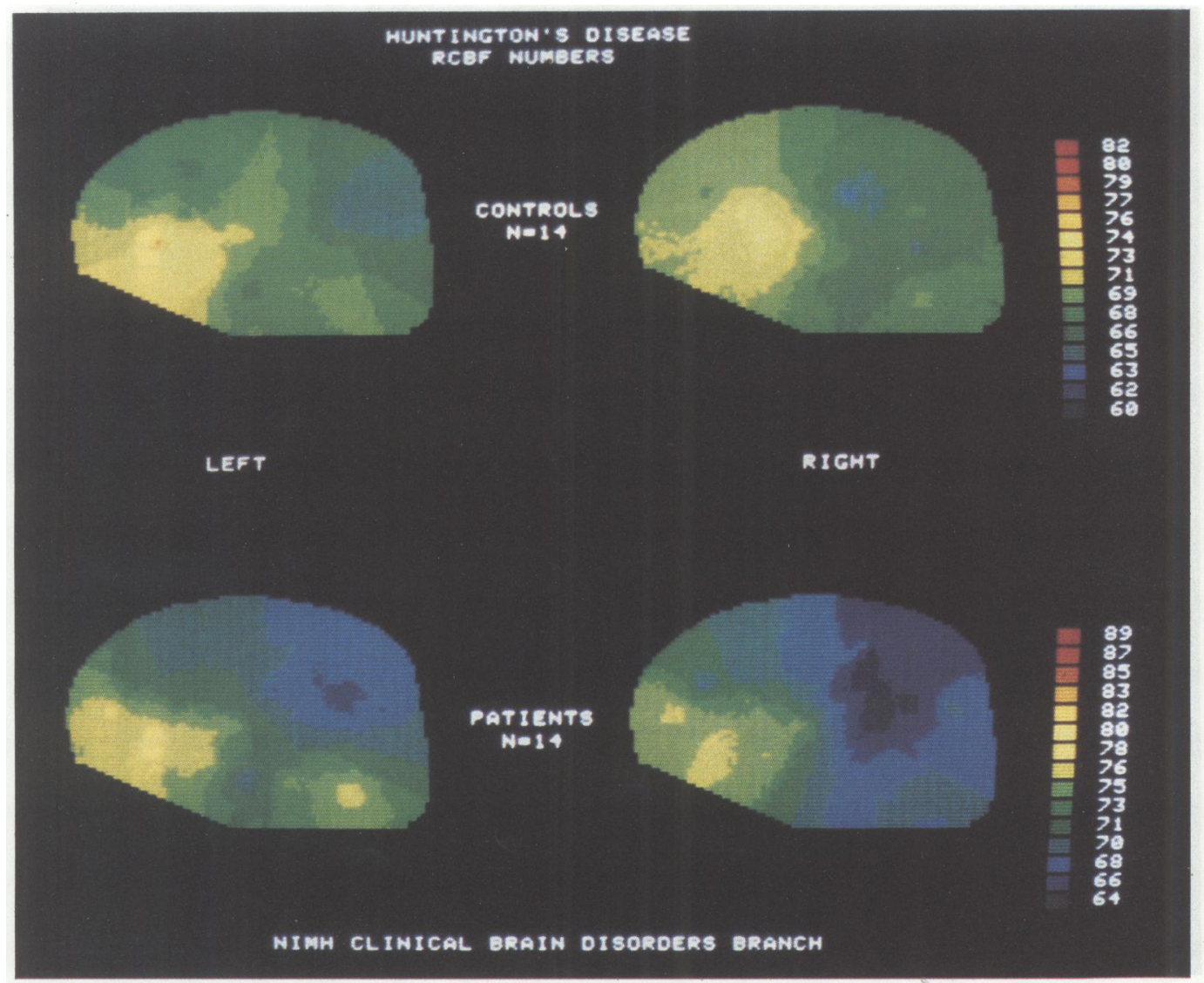

(b)

rection was made, a $2 \%$ factor was used (that is a change of $1 \mathrm{~mm} \mathrm{Hg}$ in pCO2 was equal to a $2 \%$ change in IS) ${ }^{43}$

(2) Relative distribution analysis One approach to reduce the variance in $\mathrm{rCBF}$ data and to obviate the $\mathrm{pCO} 2$ problem is to normalise regional $\mathrm{rCBF}$ values to a reference value for each brain. ${ }^{2947}$ In the present study, each absolute rCBF value was converted into a percent of the hemisphere mean blood flow and then the 32 percentage measures were collapsed into regional percent flows as described in the regional analysis above. Statistical analysis was by MANOVA for all the regions together and by ANOVA for individual regions.

(3) Specific activation analysis Because the NM condition involved many of the nonspecific activating aspects of the WCS (for example, visual stimulation, motor responses, attention, idiosyncratic emotional reactions to the test environment), an analysis of where rCBF during these two tasks differs has the greatest potential for highlighting cognitively specific cortical activation. We have previously found that this approach has an advantageous "signal-to-noise ratio" for demonstrating a relationship between $\mathrm{CCBF}$ changes and cognitive function. ${ }^{3048-50}$ Furthermore, since there were no pCO2 differences between the WCS and the NM within either group, this approach offers a means of making absolute rCBF comparisons that are not vulnerable to $\mathrm{pCO} 2$ effects or to other artifacts associated with the xenon rCBF technique (such as variations in blood volume, partition coefficients, pulmonary function). After dividing the WCS rCBF values by the NM values, in a sense "zeroing" the WCS values to the NM values, the quotient was converted to a percent and treated to the same statistical analysis as described in the regional analysis above. Statistical analyses were carried out on a mainframe computer using Statistical Analysis Systems packages (SAS 82). General linear model routines were used for MANOVA and ANOVA and correlations were examined by Pearson's product-moment test unless stated otherwise.

\section{Results}

rCBF results

Resting state During the resting state, the pattern of 


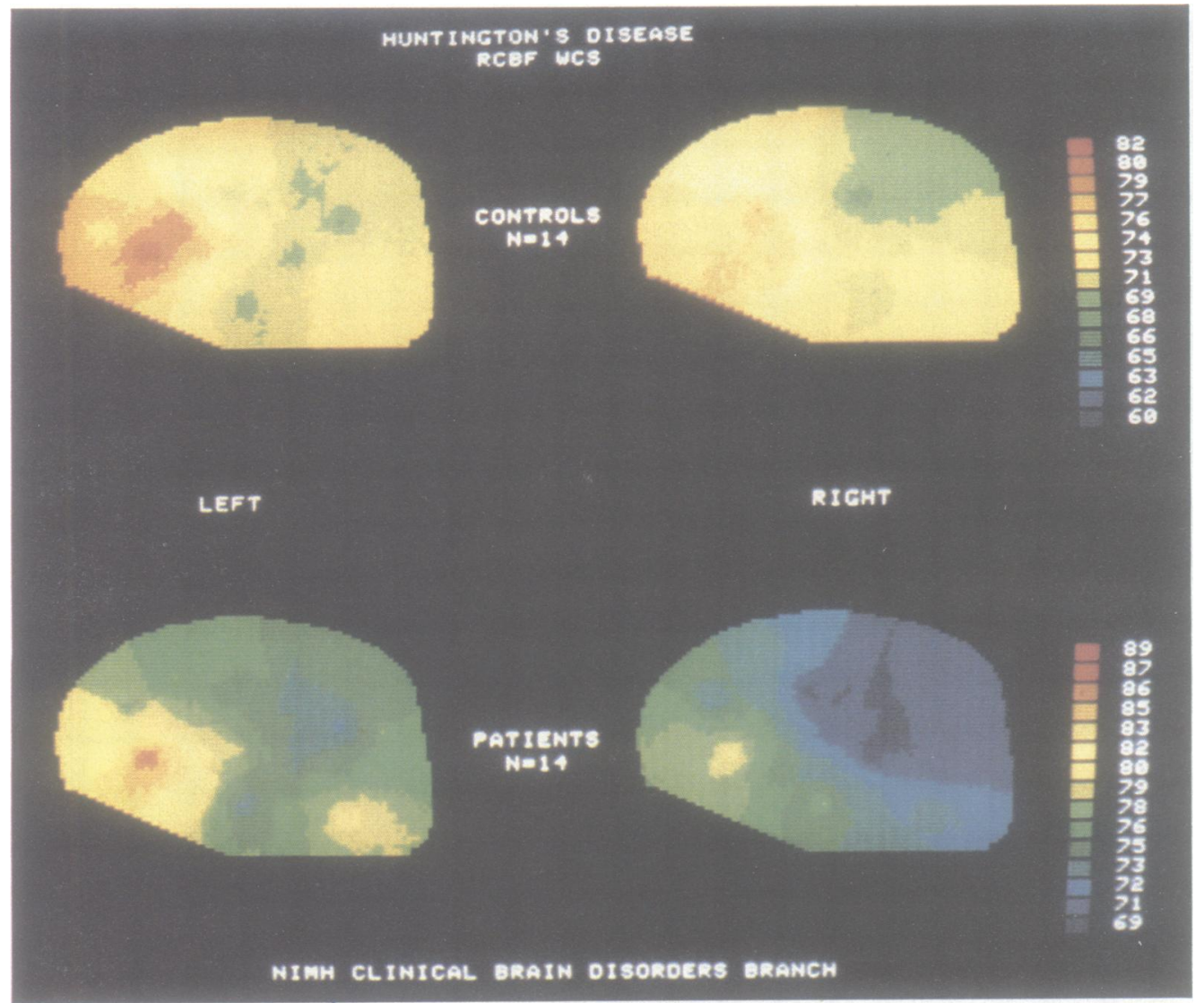

rCBF was similar in both groups (fig la). Regional analysis showed no significant group differences by MANOVA and no individual region was significantly different by univariate ANOVA, though Huntington's disease patients had slightly lower mean rCBF in each region. There was, however, a significant difference in respiratory rate and in mean end-expiratory $\mathrm{pCO} 2$ (patients, $37.1+1.4 \mathrm{~mm} \mathrm{Hg}$; controls, $46 \cdot 2+0 \cdot 9, \mathrm{p}<0.0001, t$ test $)$. $\mathrm{pCO} 2$ correction resulted in elevating $\mathrm{rCBF}$ in the Huntington's disease patients to values slightly above those of the controls, and MANOVA analysis revealed a significant overall group effect (Wilks' Lambda $=0.61, F(5,22)=2.77, \mathrm{p}<0.05)$, but no significant individual region differences (fig $2 \mathrm{a}$ ). Relative distribution analysis, as shown in fig $3 a$, revealed a trend towards an overall group effect (Wilks' Lambda $=0.63, \quad F(5,22)=2.55, \quad p<0.06)$, with Huntington's disease patients having greater relative flows to prefrontal and temporal regions.
NM Condition During the NM condition, the $\mathrm{rCBF}$ pattern was again similar in both groups (fig lb). There was no overall group effect or individual region differences in the region analysis. Despite significant differences in $\mathrm{pCO} 2$ (patients, $36 \cdot 2+1 \cdot 5$; controls, $42.5+0.9, \mathrm{p}<0.01), \mathrm{pCO} 2$ correction did not change the results of the analyses (fig $2 b$ ). Relative distribution analysis also showed no group differences (fig $3 b$ ).

WCS Condition During the WCS test, both groups again demonstrated similar rCBF patterns (fig lc, d). There were no group differences by any of the analyses (figs $2 \mathrm{c}, 3 \mathrm{c}$ ).

As depicted in fig ld, rCBF increased in both groups during the WCS as compared with during the $\mathrm{NM}$, and the increases tended to be greatest in prefrontal cortex. The results of the specific activation analysis are shown in table 1 . Despite somewhat greater mean activation in all regions in controls, 


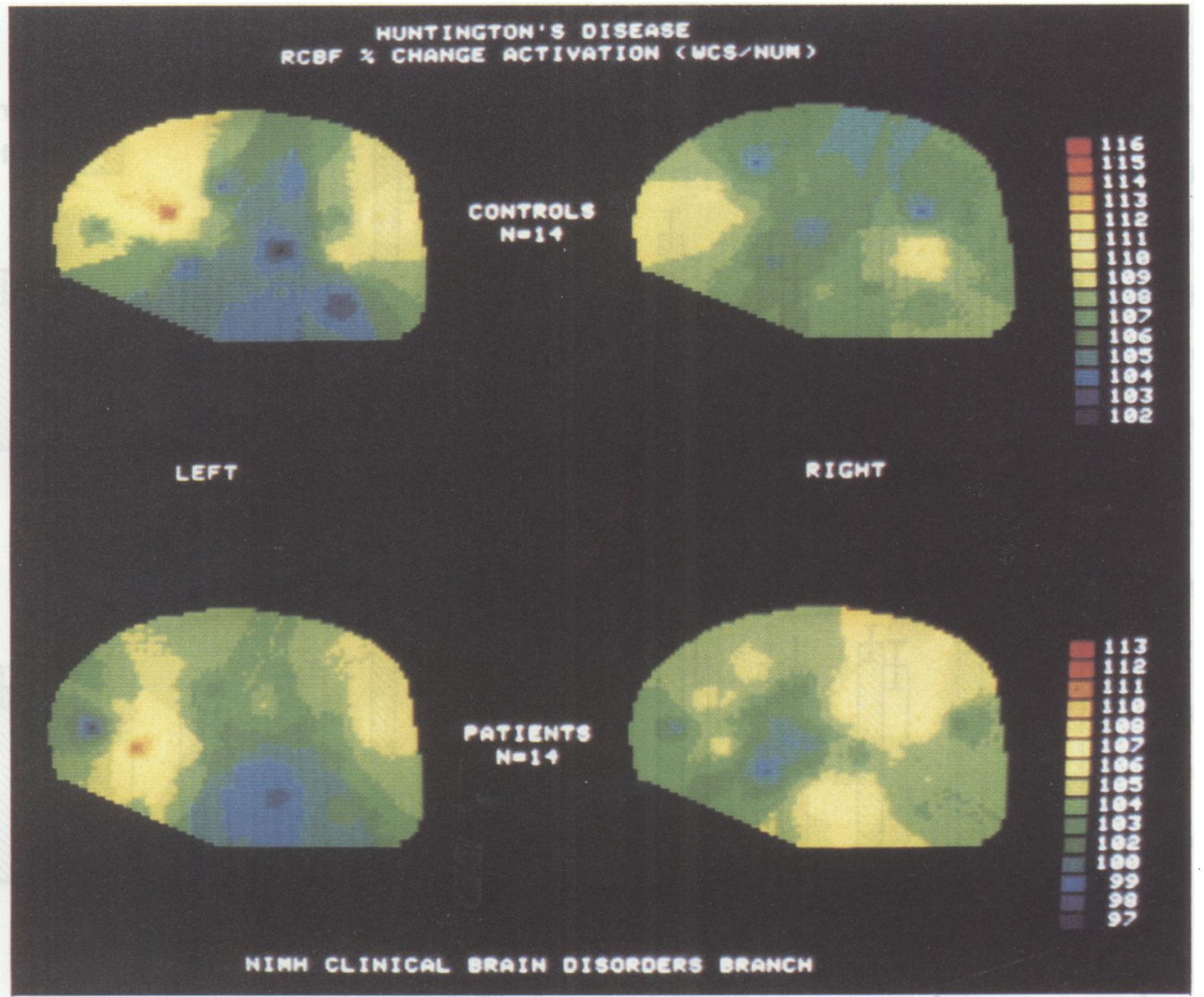

(d)

there was no overall group effect by MANOVA and in none of the individual regions was activation significantly different across groups by univariate ANOVA.

\section{$r C B F-C T$ correlations}

In both the resting state and NM condition, there were no correlations between $\mathrm{rCBF}$ in any cortical area and frontal-caudate ratio (FCR) on CT scan. During the WCS, however, degree of caudate atrophy correlated directly with $\mathrm{rCBF}$, that is, FCR and $\mathrm{rCBF}$ were inversely correlated (fig 4). It should be noted that the two patients with the lowest rCBF in fig 4 were unmedicated. Furthermore, degree of specific activation, that is percent increase in rCBF during WCS as compared with NM, also correlated significantly and inversely with FCR. Table 2 lists the magnitude of these correlations for the frontal regions. Similar correlations were found for the temporal and parietal areas. Neither rCBF during WCS nor percent activation for any cortical area correlated with age, with duration of illness, with stage of illness, or with measures of arousal that is, $\mathrm{pCO}_{2}$, pulse rate or CSF. Therefore, this behaviourally specific relationship between cortical physiology and subcortical pathology did not appear to be an artifact or epiphenomenon of differences in motor activity or in emotional experience.

\section{WCS performance correlations}

Patients performed much more poorly than did controls on the WCS (table 3). While neither rCBF during the WCS nor FCR on CT predicted cognitive performance on this test, the degree of activation over baseline showed a trend towards an inverse correlation with some measures of performance (see table 2). Performance was also correlated withindependent living skills as measured by the Shoulson and Fahn scale (Spearman rho $=0.61, \mathrm{p}<0.02$ ). Performance and years of education were not related. There were no group differences in pulse rate or GSR during any of the test conditions. 


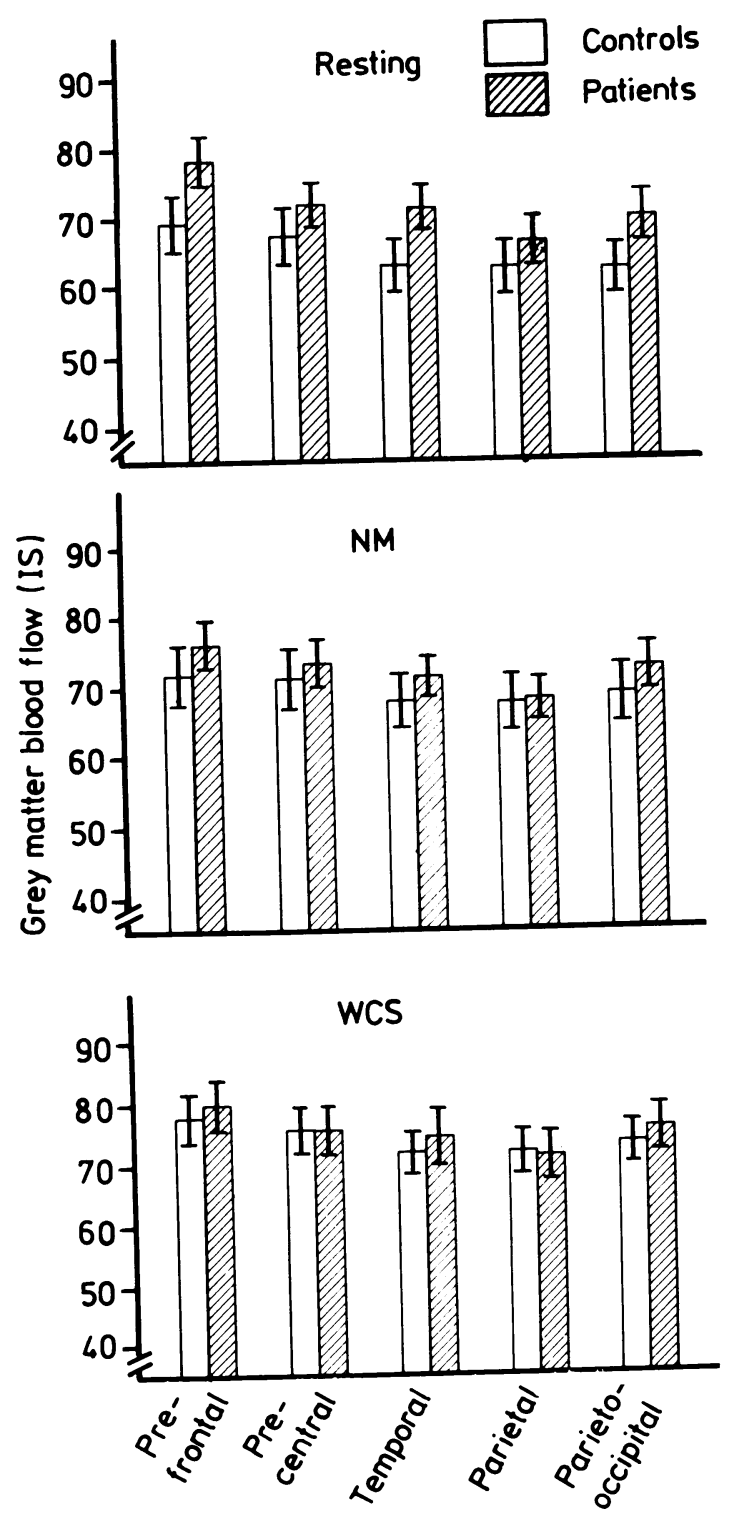

Cortical region

Fig $2 r C B F$ (mean $\pm S E M)$ in Huntington's disease patients $(N=14)$ and controls $(N=14)$ during three behavioural conditions: resting, a number matching task $(N M)$, and the Wisconsin Card Sort Test (WCS). Regional blood flow values are $\mathrm{CCO}_{2}$ corrected.

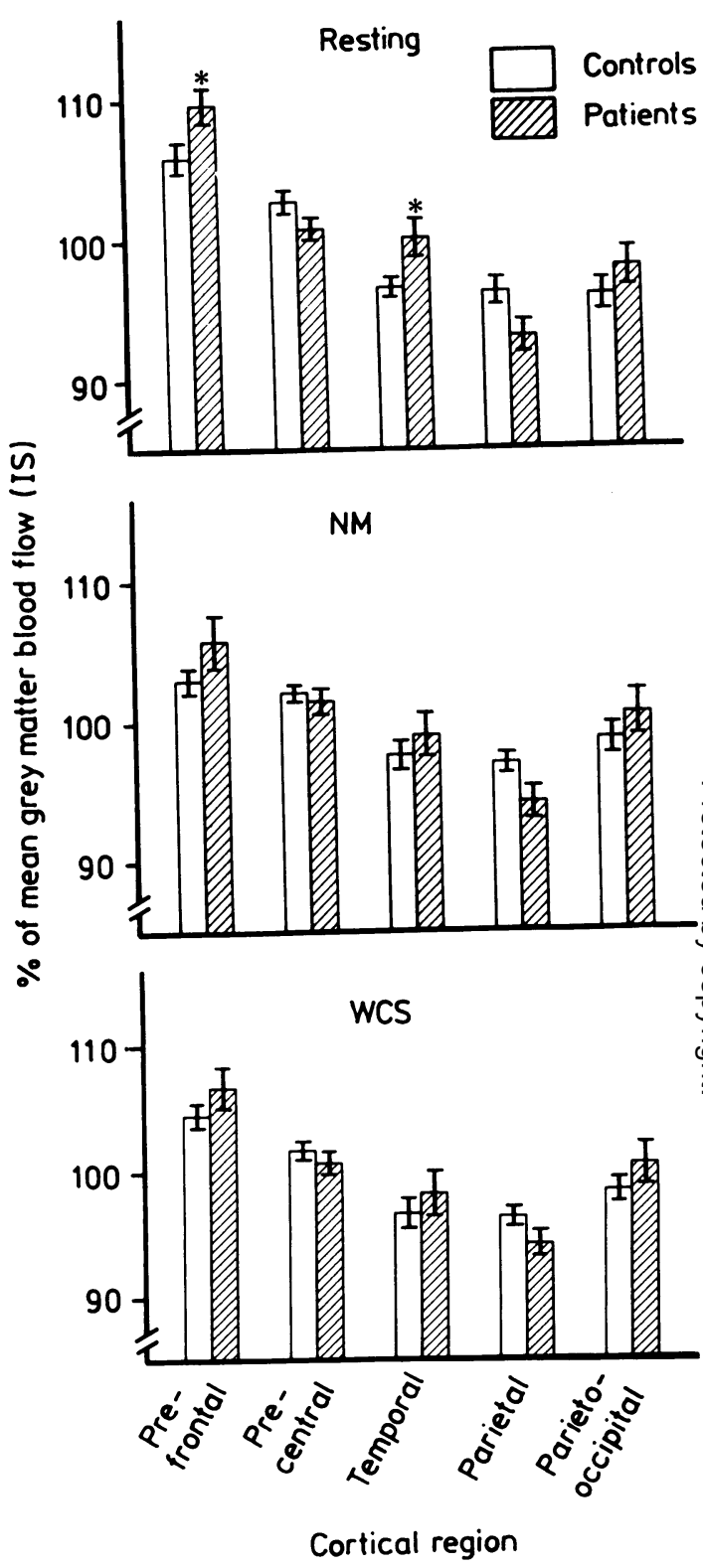

Fig $3 \quad r C B F$ in Huntington's disease patients and controls expressed as a percentage of mean brain blood flow. Bars represent mean $\pm S E M .{ }^{*} p<0.05$ by univariate (region) ANOVA across groups. 
Table 1 Comparison of percent cortical activation $(W C S / N M \times 100)($ mean \pm S.E.M. $)$

\begin{tabular}{lllll}
\hline & & & \multicolumn{2}{c}{ ANOVA } \\
\cline { 4 - 5 } Region & $\begin{array}{l}\text { Controls } \\
(N=14)\end{array}$ & $\begin{array}{c}\text { Patients }^{*} \\
(N=14)\end{array}$ & $F$ & $P$ \\
\hline Prefrontal & $9.0 \pm 3.1$ & $4.4 \pm 3.0$ & 1.1 & 0.3 \\
Precentral & $7.2 \pm 3.0$ & $2.5 \pm 1.8$ & 1.9 & 0.19 \\
Temporal & $6.6 \pm 3.0$ & $3.4 \pm 3.9$ & 0.4 & 0.5 \\
Parietal & $7.0 \pm 3.1$ & $3.6 \pm 3.0$ & 0.6 & 0.4 \\
Parieto-occipital & $7.4 \pm 2.8$ & $3.9 \pm 2.9$ & 0.8 & 0.4 \\
\hline
\end{tabular}

WCS represents Wisconsin Card Sorting Test.

NM represents Number Matching Task.

*MANOVA NS

Table 2 Frontal cortex $r C B F$ correlations

\begin{tabular}{|c|c|c|c|}
\hline & \multirow[t]{2}{*}{$\begin{array}{l}\text { FCR on } C T \\
(N=10)\end{array}$} & \multicolumn{2}{|c|}{$\begin{array}{l}\text { WCS performance } \\
(N=14)\end{array}$} \\
\hline & & Items completed & Categories \\
\hline Prefrontal rCBF & $\begin{array}{l}r=-0.63 \\
n<0.05\end{array}$ & N.S. & N.S \\
\hline $\begin{array}{c}\text { Precentral rCBF } \\
\text { during WCS }\end{array}$ & $\begin{array}{l}p=-0.62 \\
p<0.06\end{array}$ & N.S. & N.S. \\
\hline $\begin{array}{l}\% \text { prefrontal } \\
\text { activation } \\
\% \text { precentral } \\
\text { activation }\end{array}$ & $\begin{array}{l}-0.62 \\
0.06 \\
-0.71 \\
0.02\end{array}$ & $\begin{array}{l}-0.49 \\
0.07 \\
-0.57 \\
0.04\end{array}$ & $\begin{array}{l}-0.44 \\
0.12 \\
-0.43 \\
0.13\end{array}$ \\
\hline
\end{tabular}

FCR is frontal horn-caudate ratio

$\%$ activation refers to $\frac{\mathrm{WCS} \text { rCBF}}{\mathrm{NM} \text { rCBF}} \times 100$

Table 3 WCS performance results (mean \pm S.E.M.)

\begin{tabular}{lrll}
\hline & $\begin{array}{l}\text { No of items } \\
\text { completed }\end{array}$ & $\begin{array}{l}\text { No of } \\
\text { categories }\end{array}$ & $\begin{array}{l}\% \text { perseverative } \\
\text { error }\end{array}$ \\
\hline $\begin{array}{l}\text { Controls }(\mathrm{N}=14) \\
\text { Huntington's disease } \\
\text { patients* }(\mathrm{N}=14)\end{array}$ & $104 \pm 6.2$ & $6.7 \pm 0.8$ & $12.3 \pm 3.6$ \\
*All comparisons significant at $\mathrm{p}<0.01$. & $1.4 \pm 0.5$ & $38.6 \pm 6.0$ \\
\hline All comp & & & \\
\hline
\end{tabular}

Discussion

The results of this study confirm and extend earlier reports of quantitatively normal cortical metabolism in patients with mild to moderately advanced Huntington's disease. Consistent with most studies of glucose metabolism using PET, ${ }^{10-13}$ we found that cortical rCBF during the so-called "resting state" was not diminished in patients with this illness. In contrast to previous reports, we also studied Huntington's disease patients while they were engaged in a reasoning task and found that even when manifesting overt cognitive impairment, they had normal cortical rCBF and presumably cortical metabolism.

Because the "resting state" is poorly controlled in terms of patient behaviour and psychological experience and may be physiologically variable, ${ }^{5152}$ interpretation of resting brain metabolism and $\mathrm{rCBF}$ data in the context of studying mental function is problematic. $^{51}$ We have attempted to reduce interindividual variance ("noise") in rCBF data by engaging patients in explicit behaviours during the procedure and by having each subject serve as his or her own control. In the present study, one of the behaviours was selected because it appears to be mediated by cortical neuronal systems implicated in Huntington's disease and because it is usually impaired in patients with this illness. ${ }^{719}$ This was the Wisconsin Card Sorting Test (WCS), a task that places a premium on dorsolateral prefrontal cortical function. It was hypothesised that by examining cortical rCBF during cognition specifically keyed to prefrontal cortex, the relationship of prefrontal physiology to prefrontal-type cognitive deficits in Huntington's disease could be more directly appreciated.

The other explicit behaviour was a simple number matching test that posed no difficulties for Hunt-
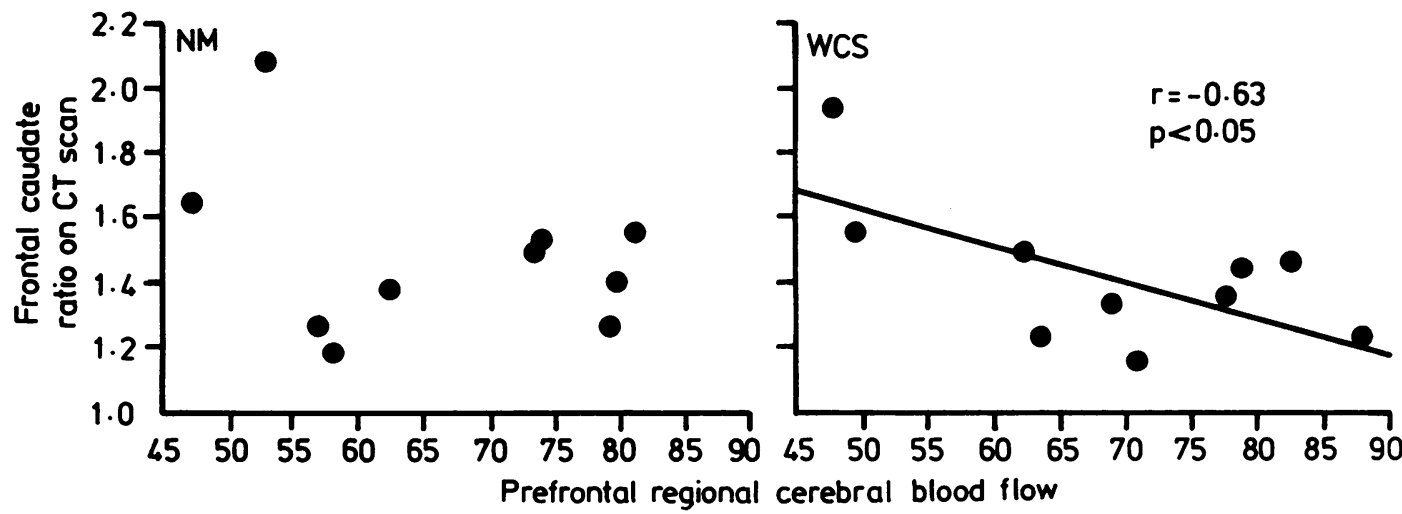

Fig 4 Correlation of prefrontal $r C B F$ with frontal-caudate ratio on CT scan. During the NM behavioural condition, the correlation was not significant $(r<0 \cdot 2, p>0 \cdot 5)$. 
ington's disease patients and that served as an rCBF baseline for comparison with rCBF during the WCS. We have previously found that by comparing $\mathrm{rCBF}$ during a regionally specific cognitive task with rCBF during an active baseline, many of the nonspecific physiological correlates of the primary task are eliminated, and rCBF that is specifically related to this task is highlighted. ${ }^{3048-50}$

Despite these efforts to isolate prefrontal physiology and to place prefrontal cortex under a selective functional "load", we could not demonstrate a reduction in prefrontal or other regional cortical activity in this Huntington's disease sample. rCBF did not differ between patients and controls during either of the explicit behavioural conditions. Furthermore, although patients did not tend to activate prefrontal cortex during the WCS over that during the NM quite as much as did the controls, this difference also was not statistically significant. These data suggest, therefore, that not withstanding the limitation of the xenon rCBF technique, prefrontal-type cognitive deficits in early Huntington's disease are the result of some mechanism other than a physiological abnormality intrinsic to prefrontal cortex.

Prefrontal-type cognitive deficits such as those typified by poor performance on the WCS are not illness specific, as they are associated with many disorders, including Alzheimer's disease, ${ }^{53}$ Parkinson's disease, ${ }^{5354}$ progressive supranuclear palsy, ${ }^{5355}$ multiple sclerosis, ${ }^{56}$ schizophrenia, ${ }^{30}$ as well as normal aging. ${ }^{35}$ It is unlikely that the pathophysiological mechanisms underlying this behavioural abnormality are the same in these pathologically and aetiologically diverse conditions. The results of in vivo brain metabolism studies may help define the various mechanisms involved. For example, in Alzheimer's disease, frontal cortex glucose metabolism and $\mathrm{rCBF}$ are typically reduced both at rest ${ }^{5-59}$ and during mental activation. ${ }^{60}$ This hypometabolic pattern is not surprising in light of findings in Alzheimer's disease of neuronal degeneration in prefrontal cortex. The results suggest that the mechanism of prefrontal-type cognitive deficits in this illness is direct impairment of intrinsic cortical processing systems.

There is also evidence from in vivo brain metabolism and $\mathrm{rCBF}$ studies of prefrontal metabolic abnormalities in patients with Parkinson's disease, ${ }^{61-63}$ progressive supranuclear palsy, ${ }^{64}$ multiple sclerosis, ${ }^{65}$ and schizophrenia, ${ }^{3066}$ though this evidence is less consistent that in Alzheimer's disease. It has been proposed that a different mechanism, namely prefrontal deafferentation, accounts for the prefrontal hypometabolism seen in Parkinson's disease, ${ }^{3738}$ in progressive supranuclear palsy, ${ }^{64}$ and in schizophrenia.$^{30}$ In a study of Parkinson's disease using a paradigm identical to the present study, the results were clearly distinct from those of Huntington's disease; we found a strong positive correlation between prefrontal rCBF and performance on the WCS. ${ }^{49}$ It is interesting to note that a similar finding emerged in a study of patients with schizophrenia. ${ }^{30}$ Whether this direct clinical-pathophysiological correlation suggests a deafferentiation mechanism for the prefrontal-type cognitive deficits seen in these disorders or not, it does suggest a different mechanism from the one implicated in this study of Huntington's disease.

Although we did not find a strong relationship between prefrontal rCBF and cognitive function in Huntington's disease, prefrontal rCBF (as well as blood flow in other cortical areas) did correlate with the degree of caudate atophy. There were two important features of this correlation. First of all, it was behaviourally specific, occurring only during the WCS condition. This novel finding suggests that the effect of caudate degeneration on cortical function is most pronounced during mental activity in which there is heightened demand for prefrontal function. Since most of the cortical input to the head of the caudate comes from prefrontal association cortex, ${ }^{6768}$ it is, perhaps, not surprising that caudate pathology preferentially disrupts the "downstream" processing of information from this source. One clinical impli-o cation of this is that patients with early Huntington's disease, who tend to have degenerative neuro- $\mathbb{Q}$ pathological changes confined to the head of the caudate, ${ }^{45}$ may evince only minimal behavioural abnormalities unless specifically engaged in mental activities that place a premium on prefrontal function, such as exercising critical judgement, planning for the future, solving complex problems, etc. This may also explain why family members and employers are often the first to perceive subtle behavioural changes.

The second feature of the relationship between caudate pathology and $\mathrm{rCBF}$ is that they were directly correlated. The greater the caudate atrophy, the more cortical rCBF was found during the WCS and the more it increased over the NM baseline. While this correlation may at first seem paradoxical, it may also represent direct physiological evidence of the mechanism of the failure of prefrontal cognitive function in Huntington's disease. It is tempting to interpret this finding as indicative of the normal physiological response of a normal prefrontal cortex to downstream blockage at the head of the caudate, the primary first order corticofugal projection site. In other words, prefrontal cortex metabolism and presumably functional output increased in proportion to the degree of its "decoupling" with caudate, as if attempting to compensate for or to get through an outflow block. The tendency for poorer performance on the WCS to be associated with greater cortical 
activation can be viewed as consistent with this interpretation.

It should be noted that while the relationship between cortical rCBF and subcortical pathology was found only during the prefrontal behavioural condition, this relationship was not confined to rCBF only in frontal cortex. The correlations with temporal and parietal rCBF are more difficult to interpret in light of the limited projections of these regions to head of caudate and also considering that these areas are not directly implicated in performing the WCS. One possibility is that changes in metabolic activity in these non-frontal association areas during the WCS is secondary to changes in prefrontal activity, an interpretation consistent with the intracortical connectivities of prefrontal cortex and with data from PET and rCBF studies indicating that metabolic activity among cortical regions is highly intercorrelated. ${ }^{69}$

Finally, while these results may be interpreted as evidence in support of the "subcortical dementia" concept, they also suggest a qualification of this concept. In the original descriptions of the "subcortical dementia" syndrome, it was conceded that the cognitive deficits were indistinguishable from those associated with frontal lobe disease. ${ }^{21} 22$ In the present study, the dementia involved a cognitive function thought to be mediated by neuronal systems intrinsic to prefrontal cortex. There is no compelling reason to believe that the dementia itself is subcortical simply because the primary pathology is located there. The data presented here suggest that the dementia represents a loss of neocortical (particularly prefrontal) function and that the role of subcortical pathology is in determining the pathophysiologic mechanism by which this function is lost.

We are especially grateful to Marjorie Gillespie, RN for invaluable assistance. We thank Susan Folstein, MD and Thomas Chase, MD for granting permission to study some of their patients. Sarah Rosenbaum and Catherine Brasher helped with graphics and Gail A Miller helped prepare the manuscript.

\section{References}

1 Bruyn GW. Huntington's chorea: historical, clinical, and laboratory synopsis. In: Vinken P, Bruyn GW, eds. Handbook of Clinical Neurology, vol 6. Amsterdam: Elsevier, 1968:298-378.

2 Chandler JH, Reed TE, DeJong RN. Huntington's chorea in Michigan. III. Clinical observations. Neurology 1960;10: 148-53.

3 Bruyn GW. Neuropathological changes in Huntington's chorea. In: Barbeau A, Chase TN, Paulson GW, eds. Advances in Neurology, vol 1. New York: Raven Press. 1973:399-403.

4 Bryn GW, Bots G Th, Dom R. Huntington's chorea: Current neuropathological status. In: Chase TN, Wexler NS, Barbeau A, eds. Advances in Neurology, vol 23. New York: Raven Press. 1979:83-93

5 Von Sattel JP, Myers RH, Stevens TJ, Ferrante RJ, Bird ED,
Richardson Jr, P. Neuropathologic classification of Huntington's disease. J Neuropathol Exp Neurol 1985;44:559-77.

6 Nemeroff CB, Youngblood WW, Manberg RI. Regional brain concentrations of neuropeptides in Huntington's chorea and schizophrenia. Science 1983;221:972-5.

7 Josiassen RC, Curry LM, Mancall EL. Development of neuropsychological deficits in Huntington's disease. Arch Neurol 1983;40:791-6.

8 Sax DS, O'Donnell B, Butters N, Menzer L, Montgomery K, Kayne HL. Computed tomographic, neurologic, and neuropsychological correlates of Huntington's disease. Int J Neurosci 1983;18:21-36.

9 Neophytides AN, DiChiro G, Barron SA, Chase TN. Computed axial tomography in Huntington's disease and persons at risk for Huntington's disease. In: Chase TN, Wexler NS, Barbeau A, eds. Advances in Neurology, vol 23. New York: Raven Press, 1979:185-91.

10 Kuhl DE, Phelps ME, Markham CH, Mettler EJ, Riege WH, Winter J. Cerebral metabolism and atrophy in Huntington's disease determined by ${ }^{18} \mathrm{FDG}$ and computed tomographic scan. Ann Neurol 1982;12:425-34.

11 Mazziotto JC, Wapenski J, Phelps ME, et al. Cerebral glucose utilization and blood flow in Huntington's disease: Symptomatic and at-risk subjects. J Cereb Blood Flow Metab 1985; Suppl. 1:25-6.

12 Hayden MR, Martin WRW, Stoessl AJ, et al. Positron emission tomography in the early diagnosis of Huntington's disease. Neurology 1986;36:888-94.

13 Young AB, Penney JB, Starosta-Rubenstein S, et al. PET scan investigations of Huntington's disease: Cerebral metabolic correlates of neurological features and functional decline. Ann Neurol 1986;20:296-303.

14 Huntington G. On chorea, The Medical and Surgical Reporter, 1872, XXVI, 320-1.

15 Caine ED, Hunt RD, Weingartner H, Ebert MH. Huntington's dementia: Clinical and neuropsychological features. Arch Gen Psychiatry 1978;35:377-84.

16 Butters N, Sax D, Montgomery K, Tarlow S. Comparison of the neuropsychological deficits associated with early and advanced Huntington's disease. Arch Neurol 1978;35:585-9.

17 Wexler NS. Perceptual-motor, cognitive, and emotional characteristics of persons at risk for Huntington's disease. In: Chase TN, Wexler NS, Barbeau A, eds Advances in Neurology, vol 23. New York: Raven Press. 1979:257-271.

18 Fedio P, Cox CS, Neophytides A, Canal-Frederick G, Chase TN. Neuropsychological profile of Huntington's disease: patients and those at risk. In: Chase TN, Wexler NS, Barbeau A, eds Advances in Neurology, vol 23. New York: Raven Press. 1979:239-55.

19 Fisher JM, Kennedy JL, Caine ED, Shoulson I. Dementia in Huntington's disease: A cross-sectional analysis of intellectual decline: In: Mayeux R, Rosen WG, eds. The Dementias. New York: Raven Press. 1983:229-38.

20 McHugh PR, Folstein MF. Psychiatric syndromes of Huntington's disease: A clinical and phenomenological study. In: Benson DF, Blumer D, eds. Psychiatric Aspects of Neurólogic Disease. New York: Grune and Stratton 1975:267-86.

21 Albert ML, Feldman RG, Willis AL. The subcortical dementia of progressive supranuclear plasy. J Neurol Neurosurg Psychiatry 1974;37:121-30.

22 Albert ML. Subcortical dementia. In: Katzman R, Terry RD, Bick KL, eds. Alzheimer's Disease: Senile Dementia and Related Disorders. New York: Raven Press 1978:173-96.

23 Cummings JL, Benson F. Subcortical dementia: Review of an emerging concept. Arch Neurol 1984;41:874-9.

24 Steven J, Huber MA, Paulson GW. The concept of subcortical dementia. Am J Psychiatry 1985:142:1312-7.

25 Mayeux R, Stern Y, Rosen J, Benson F. Is subcortical dementia a recognizable clinical entity? Ann Neurol 1983;14:278-83.

26 Whitehouse PJ. The concept of subcortical and cortical dementia: 
Another look. Ann Neurol 1986;19:1-6.

27 Shoulson I, Fahn S. Huntington's disease: Clinical care and evaluation. Neurology 1979;29:1-3.

28 Obrist WD, Thompson HK, Wang HS, Wilkinson WE. Regional cerebral blood flow estimated by 133 Xenon inhalation. Stroke 1975;6:245-56.

29 Deshmukh VD, Meyer JS. Noninvasive Measurement of Cerebral Blood Flow. Englewood Cliffs, New Jersey: Prentice-Hall Inc. 1978.

30 Weinberger DR, Berman KF, Zec RF. Physiological dysfunction of dorsolateral prefrontal cortex in schizophrenia. I: Regiona cerebral blood blow (rCBF) evidence. Arch Gen Psychiatry 1986;43:114-25.

31 Coppola R, Buchsbaum MS, Rigal F. Computer generation of surface distribution maps of measures of brain activity. Comput Biol Med 1982;12:191-9.

32 Obrist WD, Wilkinson WE. The non-invasive Xe-133 method Evaluation of CBF indices. In: Bes A, Geraud G, eds. Cerebral Circulation. Amsterdam: Elsevier North Holland Inc., 1980:119-24.

33 Risberg J, Maxmilian V, Prohovnik I. Changes of cortical activity patterns during habituation to a reasoning test: A study of the $133 \mathrm{Xe}$ inhalation technique for measurement of regional cerebral blood flow. Neuropsychologia 1977;15:793-8.

34 McHenry LC, Merony J, Bass E, et al. Xenon 133 inhalation method. for regional cerebral blood flow measurements: Normal values and test-retest results. Stroke 1978;9:396-9.

35 Heaton RK. The Wisconsin Card Sorting Test Manual, Odessa, Florida, Psychological Assessment Resources, 1981.

36 Milner N. Effects of different brain lesions on card sorting. Arch Neurol 1963;9:100-10.

37 Milner B. Interhemispheric differences in the localization of psychological processes in man. Br Med Bull 1971;27:272-7.

38 Stuss DT, Benson DF. Frontal lobe lesions and behavior. In: Kertesz A, ed. Localization in Neuropsychology. New York: Academic Press Inc. 1983:429-54.

39 Milner B. Some effects of frontal lobectomy in man. In: Warren JM, Akert K, eds. The Frontal Granular Cortex and Behavior. New York: McGraw-Hill Book Co. 1963:313-34.

40 Barr AN, Heinze WJ, Dobben GD, Valvassori GE, Sugar O. Bicaudate index in computerized tomography of Huntington disease and cerebral atrophy. Neurology 1978;28:1196-200.

41 Yamamato M, Meyer JS, Sakai F, Yamaguchi F. Aging and cerebral vasodilator responses to hypercarbia: Responses in normal aging and in persons with risk factors for stroke. Arch Neurol 1980;37:489-96.

42 Maxmilian VA, Prohovnik I, Risberg J. Cerebral hemodynamic response to mental activation in normo and hypercapnia. Stroke 1980;11:342-7.

43 Davis SM, Ackerman RH, Correia JA, et al. Cerebral blood flow and cerebrovascular $\mathrm{CO}_{2}$ reactivity in stroke-age normal controls. Neurology 1983;33:391-9.

44 Prohovnik I. Mapping Brainwork. Lund, Sweden, Liber, 1980.

45 Gur RC, Gur RE, Obrist WD, et al. Sex and handedness differences in cerebral blood flow during rest and cognitive activity. Science 1982;217:659-61.

46 Evans MC, Cameron IR. Adaption of rCBF during chronic exposure to hypercapnia and to hypercapnia with hypoxia. J Cereb Blood Flow Metab 1981; Suppl 1:435-6.

47 Risberg J. Regional cerebral flow measurements by 133 Xenon inhalation: Methodology and applications in neuropsychology and psychiatry. Brain Lang 1980;9:9-34.

48 Berman KF, Zec RF, Weinberger DR. Physiologic dysfunction of dorsolateral prefrontal cortex in schizophrenia. II. Role of neuroleptic treatment, attention, and mental effort. Arch Gen Psychiatry 1986;43:126-35.

49 Weinberger DR, Berman KF, Chase TN. Prefrontal cortex phys- iological activation in Parkinson's disease: Effect of L-dopa. Neurology 1986;36 Suppl 1:170.

50 Weinberger DR, Berman KF. Activation of inferior parietalposterior temporal cortex in Alzheimer's disease: An rCBF study. Neurology 1986;36 Suppl 1:132-3.

51 Lassen NA, Roland PE. Localization of cognitive function with cerebral blood flow. In: Kertesz A, ed. Localization in Neuropsychology. New York: Academic Press Inc, 1983:141-52.

52 Duara R, Gross-Glenn K, Sevush S, et al. Intra-individual and inter-individual variability in cerebral glucose metabolism in the resting state and during psychological activation. $J$ Cereb Blood Flow Metab 1985;5 Suppl 1:217-8.

53 Pillon B, Dubois B, Lhermitte F, Agid Y. Heterogeneity of cognitive impairment in progressive supranuclear palsy, Parkinson's disease and Alzheimer's disease. Neurology 1986;36:1179-85.

54 Bowen FP. Behavioural alterations in patients with basal ganglia lesion. In: Yahr MD, ed. The Basal Ganglia. New York: Raven Press. 1976:169-83.

55 Maher ER, Smith EM, Lees AJ. Cognitive deficits in the SteeleRiehardson-Olszewski syndrome (progressive supranuclear palsy). J Neurol Neurosurg Psychiatry 1985;48:1234-9.

56 Caine ED, Bamford KA, Schiffer RB, Shoulson I, Levy S. A controlled neuropsychological comparison of Huntington's disease and multiple sclerosis. Arch Neurol 1986;43:249-54.

57 Frackowiak RSJ, Pozzilli C, Legg NJ, et al. Regional cerebral oxygen supply and utilization in dementia: A clinical and physiological study with oxygen-15 and positron tomography. Brain 1981;104:753-78.

58 Friedland RP, Budinger TF, Ganz E, et al. Regional cerebral metabolic alterations in dementia of the Alzheimer type: Positron emission tomography with ${ }^{18} \mathrm{~F}$ fluorodeoxyglucose. J Comp Assist Tomography 1983;7(4):590-8.

59 Foster NC, Chase TN, Mansi L. et al. Cortical abnormalities in Alzheimer's disease. Ann Neurol 1984;16:649-54.

60 Ingvar DH, Risberg J, Schwartz MS. Evidence of subnornal function of association cortex in presenile dementia. Neurology 1975;25:964-74

61 Bès A, Guell A, Fabre N, Dupui Ph, Victor G, Géraud G. Cerebral blood flow studied by Xenon-133 inhalation technique in Parkinsonism: Loss of hyperfrontal pattern. J Cereb Blood Flow Metab 1983;3:33-7.

62 Perlmutter JS, Raichle ME. Regional blood flow in hemiparkinsonism. Neurology 1985;35:1127-34.

63 Wolfson LI, Leenders KL, Brown LL, Jones T. Alterations of regional cerebral blood flow and oxygen metabolism in Parkinson's disease. Neurology 1985;35:1399-405.

64 D'Antona R, Baron JC, Samson Y, et al. Subcortical dementia: Frontal cortex hypometabolism detected by positron tomography in patients with progressive supranuclear palsy. Brain 1985;108:785-99.

65 Eidelman BH, Hospodar M, Ratcliff G, Gur D, Yonas H. Dementia and cerebral blood flow in multiple sclerosis. Neurology 1984;35 Suppl 1:316.

66 Weinberger DR, Kleinman JE. Observations on the brain in schizophrenia. In: Hales RE, Frances AJ, eds. Psychiatry Update 1986. American Psychiatric Association Annual Review, Volume V. Washington: APA Press, 1986:42-67.

$67 \mathrm{Kemp}$ JM, Poewell TPS. The cortico-striate projection in the monkey. Brain 1970;93:525-46.

68 Goldman PS, Nauta WJH. An intricately patterned prefrontocaudate projection in the rhesus monkey. J Comp Neurology 1977;171:369-86.

69 Metter EJ, Riege WH, Kameyama M, Kuhl DE, Phelps ME: Cerebral metabolic relationships for selected brain regions in Alzheimer's, Huntington's and Parkinson's Diseases. J Cereb Blood Flow Metab 1984;4:500-6. 